\title{
Effectiveness of Music Therapy on Aggressive Behavior of Visually Impaired Adolescents
}

\author{
Peyman Hashemian1, Norouz Mashoogh ${ }^{2}$, Lida Jarahi ${ }^{3 *}$ \\ ${ }^{1}$ Psychiatry and Behavioral Sciences Research Center, Faculty of Medicine, Mashhad University of Medical \\ Sciences, Mashhad, Iran \\ ${ }^{2}$ Ghochan Azad University, Ghochan, Iran \\ ${ }^{3}$ Addiction Research Center, Faculty of Medicine, Mashhad University of Medical Sciences, Mashhad, Iran \\ Email: Jarahil@mums.ac.ir
}

Received 25 January 2015; accepted 5 March 2015; published 10 March 2015

Copyright (C) 2015 by authors and Scientific Research Publishing Inc.

This work is licensed under the Creative Commons Attribution International License (CC BY). http://creativecommons.org/licenses/by/4.0/

\section{(c) (i) Open Access}

\begin{abstract}
Objective: Aggression is one of the common social disorders in adolescence. Blindness is a disability, which can lead to immature and inappropriate behaviors in children, and increase aggression in teenagers. The present study was conducted to investigate the effect of music on aggressive behavior in visually impaired students. Methods: This research was an experimental pretest-posttest study with a control group and was conducted in 2012. The study population of this research was teenagers with visual impairments in Bojnord, northeast of Iran. For this purpose, Buss and Perry aggression questionnaire and Rutter behavior questionnaire for teachers were used. Twelve music therapy sessions were held, each lasting 90 minutes. T-tests and analysis of covariance (ANCOVA) were used for data analysis. Results: There were not significant differences between the two groups regarding age, socioeconomic status, and education level of parents, as ascertained prior to the pre-test. In the intervention group, the declines of aggression scores were statistically significant. There were significant differences between the results of post-test in the intervention and control groups. Conclusion: Music therapy reduces aggression in teens with blindness and can be used as a non-pharmacological intervention to reduce emotional states in this group.
\end{abstract}

\section{Keywords}

Aggression, Music Therapy, Visually Impaired Student

\footnotetext{
${ }^{*}$ Corresponding author.
}

How to cite this paper: Hashemian, P., Mashoogh, N. and Jarahi, L. (2015) Effectiveness of Music Therapy on Aggressive Behavior of Visually Impaired Adolescents. Journal of Behavioral and Brain Science, 5, 96-100. 


\section{Introduction}

Aggression is one of the more prevalent social disorders in adolescence [1]. Adolescents are more susceptible to aggressive behavior, when they are not given a positive response to their natural demands; they are more prone to behavioral problems, including aggression [2].

From a neurological perspective, the nervous system and endocrine glands are considered to be the physiological basis of aggressive behavior [3]-[5]. Some researchers consider aggression as a learned social behavior. Berkowitz believes that previous disturbing events lead to a greater tendency toward aggression and desertion [6]. Moreover, the occurrence of aggressive and deserted behavior depends on higher levels of cognitive process. It is known that these behaviors have resulted from incomplete or inaccurate modeling, due to inadequate and poor communication with the others. People with disabilities, especially blind people, are at a higher risk for acquiring inappropriate and ineffective behaviour patterns [7] [8].

Children with disabilities are not often able to engage in social interaction with peers and adults, and their social and emotional adjustment is more difficult in future interactions. According to WHO reports, blindness in school-age children is less prevalent than in adults, and its prevalence is increased with an increasing age [9]. Children with visual impairments remain more aloof and isolated and may show immature and inappropriate behaviors. Blind adolescents are more worried about their future, are less able to suppress their own anger and aggression, have negative attitudes towards themselves, and suffer "learned helplessness" that will aggravate frustration.

Many findings show that music is essentially a biological phenomenon and has a significantly positive impact on humans' behaviors [10]-[12]. Music therapy is used for the treatment of some physical, emotional, and psychological disorders [12] [13]. Pain, anxiety, grief, and relationship troubles are the most common issues that are tried to treat with applying music [14]-[16]. Playing and listening to music can release the endorphins, modulate emotions and relieve pain [17] [18]. Also, music changes the functions of the nervous, hormonal and autonomic nervous system, resulting in a positive impact on stress, satisfaction, and self-confidence [19].

In a study, social skills were evaluated in a group of children with visual impairment. The results of that study showed that according to the teachers the most common problems of children with blindness included restlessness, distractibility, bullying, fighting, interrupting the conversation, anger, spite, aggression and inability to control aggressive behavior [20]. Because of intrinsic interest and motivation, music creates an appropriate and safe environment for social interactions and motivates positive self-interest. Music also reduces social indifference, isolation, lack of pleasure, and violence. People with blindness are more reliant on audio devices to perceive the world around them; different audio devices allow them to make representations of the outside world. We didn't found the music therapy study that targeted aggression in blind teenagers or other teenagers. The present study was conducted to investigate the effect of music on decreasing aggression in high school students with blindness.

\section{Methods}

The present research was an experimental study with a randomized pretest-posttest design. This study was conducted on male and female visually impaired high school students in Bojnord city, Iran, 2012. In this study, music was used for improving learning, social adjustment, muscle coordination, emotional stability, and emotional stimulation in these students.

According to the statistical method used (analysis of covariance) with alpha error at 0.05 and the average effect size of 0.25 which was calculated using Cohen's table, the size of each group was estimated to be 28 (in a total of 56 people) by $G^{*}$ Power program. Students voluntarily consented to participate in the study and were enrolled by using random sampling method. Afterward, the study participants were randomly divided into treatment and control groups.

Demographic data including parental education level and economic status of the family were collected. Aggression was evaluated before and after music therapy sessions in both the control and experimental groups. In the present study, aggression was operationally defined as participants' score in the Buss and Perry aggression questionnaire and Rutter behavior questionnaire for teacher (hereafter, the Buss and Perry test and the Rutter test, respectively). Independent variable was music therapy, and the dependent variable was aggression level.

The current version of Buss and Perry aggression questionnaire which consisted of 29 questions was used. The Buss and Perry aggression questionnaire has good internal reliability. Cronbach's alpha coefficient is valid 
for physical and verbal aggression subscales, hostility, and violence. Buss and Perry have reported that perpetuity of this test and the internal consistency of these four factors are between 0.72 and 0.8 . The questionnaire measures four aspects of aggression: physical aggression, verbal aggression, anger and hostility, and total amount of aggression. The Rutter test has a total of 30 items and 5 subscales including aggression and hyperactivity (7 items), social conflict (6 items), antisocial behaviors ( 7 items) and attention deficit (5 questions). This test has an internal consistency coefficient of 0.76 .

In order to perform music therapy using traditional folk songs, traditional music sessions were held for tar, santour, flute, and guitar. The music therapy treatment consisted of twelve 90-minute semi-private sessions with a week apart; the sessions were held in four classes with a group size of 7 students each. The same musical melodies were played equally in all groups. Meeting framework and instruction guides were identical for the four classes. For control group, no intervention was used and they were not asked to attend to any music therapy sessions. After completing all therapy sessions, students were re-tested and aggression levels were calculated. Kolmogorov-Smirnov and t-tests were performed for assessing normality. The effectiveness of music therapy was evaluated on decreasing aggression in visually impaired students' by using analysis of covariance (ANCOVA).

\section{Result}

The mean age of participants was $16.11 \pm 0.95$ and $16.46 \pm 0.88$ in treatment and control groups, respectively (P $=0.152$ ). Study participants in two groups were similar according to age, level of parental education, economic status, and level of aggression before the intervention (Buss and Perry and Rutter test scores).

Pretest and posttest score of aggression (according to the Buss and Perry test) in the experimental group was $72.61 \pm 11.06$ and $63.04 \pm 8.90$, respectively. These scores were $72.18 \pm 11.45$ (pretest) and $71.46 \pm 10.56$ (posttest) in control group. Also according to Rutter test, the mean and standard deviation of the pretest and posttest aggression scores in the experimental group were $10.61 \pm 3.39$ and $7.68 \pm 2.53$, respectively. On the other hand, the means of pretest and posttest aggression in the control were $11.82 \pm 4.09$ and $10.86 \pm 2.97$, respectively.

The Buss and Perry test scores analysis showed that the music can significantly reduce the level of aggression. Significant differences were also observed in the scores of both the intervention and control groups that were treated with music therapy $(\mathrm{P}=0.02)$ (Table 1$)$. Analysis of Rutter test scores showed that the effect of music on decreasing aggression was significant. There were significant differences between experimental and control groups with respect to the effect of music therapy on aggression levels $(\mathrm{P}=0.01)$ (Table 2$)$.

\section{Discussion}

The results showed that, based on scores from the Buss and Perry test and the Rutter test scores, music had significant effect on reducing aggression.

Habibipour and colleagues in their study investigate the effect of Iranian nonverbal soft music on the reduction of aggression among boys of the Mashhad guidance school [20]. For this purpose, 30 young male students were randomly selected as study groups. The same version of the Buss and Perry test was used for data collec-

Table 1. Co-variance analysis of buss and perry aggression questionnaire scores.

\begin{tabular}{cccccc}
\hline & Variable & Df & Mean square & F & P \\
\hline Intervention & Aggression & 1 & $20 / 094$ & $8 / 596$ & $0 / 005$ \\
Intervention *Group (interaction) & Aggression & 2 & $2868 / 173$ & $351 / 757$ & $0 / 001$ \\
\hline
\end{tabular}

Table 2. Co-variance analysis of rutter questionnaire scores.

\begin{tabular}{ccccc}
\hline & Variable & Df & Mean square & F \\
\hline Intervention & Aggression & 1 & $17 / 949$ & $12 / 781$ \\
Intervention *Group (interaction) & Aggression & 2 & $242 / 277$ & $175 / 522$ \\
\hline
\end{tabular}


tion. The results showed that there is significant positive association between Iranian nonverbal soft music on the reduction of physical and verbal aggression and violence among students. Similarly, Smeijsters and Cleven reviewed the evidence for the effectiveness of art including music, drama, and dance therapy in reducing aggression [21].

Results of studies in this area showed that these treatments were extremely helpful in preventing recurrence of treated disorders. Also, aggressive behaviors and aggression showed positive changes to the art based treatments, especially music. Saarikallio and Erkkila (2007) studied the role of music in the regulation of emotional states in adults [22]. A study conducted by Labbé et al., demonstrated that listening to classical or self-selected relaxing music will reduce anxiety, anger, and arousal of the sympathetic nervous system after exposure to stressors [23]. They concluded that music therapy can facilitate the nonverbal expression of emotion.

The results of this study showed the effect of listening to music on reducing aggression and aggressive behavior in visually impaired students. Accordingly, it can be suggested that music had therapeutic effects on aggression, and musical interventions are effective for aggressive behavior in visually impaired students. Like all other behaviors, aggressive behavior follows learning principles. Therefore, based on the principles of respondent and instrumental (operant) conditioning, it is possible to explain the nature of aggression. The music is not only a desirable alternative response to changing behavior in study participants, but is one of the tools that can directly affect emotions, feelings, and imagery, and can also indirectly influence individual recognition.

The results of this study had suitable validity due to the use of self-report measure and other measuring tools. Because, Buss and Perry aggression questionnaire has often focused on aggression which is an experience by person, while Rotter test has focused on measuring aggressive behavior. The results of both aggression tests have confirmed the effectiveness of music on reducing aggression and aggressive behaviors in visually impaired children.

\section{Conclusion}

This paper expressed effectiveness of music therapy on aggressive behavior of visually impaired adolescents. Music therapy reduces aggression in teens with blindness and can be used as a non-pharmacological intervention to reduce emotional states in this group.

\section{Limitation and Suggestion}

While this study is not novel by any means, it does fill a gap in our knowledge; literature searches produced studies with children and adults, and often those with comorbid disorders, or a different disorder entirely. We did not find a music therapy study that targeted aggression and used blind teenagers who are otherwise healthy as subjects. This is crucial to moving music therapy forward and to make it recognized as a legitimate therapeutic method for many populations (especially by insurance companies). We suggest further researches to be performed on healthy subjects as well.

\section{References}

[1] Baumeister, R.F., Bushman, B.J. and Campbell, W.K. (2000) Self-Esteem, Narcissism, and Aggression: Does Violence Result from Low Self-Esteem or from Threatened Egotism? Current Directions in Psychological Science, 9, 26-29.

[2] Bettencourt, B.A., Talley, A., Benjamin, A.J. and Valentine, J. (2006) Personality and Aggressive Behavior under Provoking and Neutral Conditions: A Meta-Analytic Review. Psychological Bulletin, 132, 751-777. http://dx.doi.org/10.1037/0033-2909.132.5.751

[3] Berenbaum, S.A. and Resnick, S.M. (1997) Early Androgen Effects on Aggression in Children and Adults with Congenital Adrenal Hyperplasia. Psychoneuroendocrinology, 22, 505-515. http://dx.doi.org/10.1016/S0306-4530(97)00049-8

[4] Chang, C., Li, C.Y., Earley, R.L. and Hsu, Y. (2012) Aggression and Related Behavioral Traits: The Impact of Winning and Losing and the Role of Hormones. Integrative and Comparative Biology, 52, 801-813. http://dx.doi.org/10.1093/icb/ics057

[5] Marti-Carbonell, M.A., Darbra, S., Garau, A. and Balada, F. (1992) Hormones and Aggression. Archivos de neurobiologia, 55, 162-174.

[6] Berkowitz, L. (1989) Frustration-Aggression Hypothesis: Examination and Reformulation. Psychological Bulletin, 106, 59-73. http://dx.doi.org/10.1037/0033-2909.106.1.59 
[7] Hughes, K., Bellis, M.A., Jones, L., Wood, S., Bates, G., Eckley, L., et al. (2012) Prevalence and Risk of Violence against Adults with Disabilities: A Systematic Review and Meta-Analysis of Observational Studies. The Lancet, 379, 1621-1629. http://dx.doi.org/10.1016/S0140-6736(11)61851-5

[8] Berkowitz, L. (1990) On the Formation and Regulation of Anger and Aggression: A Cognitive-Neoassociationistic Analysis. The American Psychologist, 45, 494-503. http://dx.doi.org/10.1037/0003-066X.45.4.494

[9] Roodhooft, J.M.J. Leading Causes of Blindness Worldwide. Bulletin de la Societe belge d'ophtalmologie, 283, 19-25.

[10] Robb, S.L., Burns, D.S., Stegenga, K.A., Haut, P.R., Monahan, P.O., Meza, J., et al. (2014) Randomized Clinical Trial of Therapeutic Music Video Intervention for Resilience Outcomes in Adolescents/Young Adults Undergoing Hematopoietic Stem Cell Transplant: A Report from the Children's Oncology Group. Cancer, 120, 909-917. http://dx.doi.org/10.1002/cncr.28355

[11] Fritz, T.H., Halfpaap, J., Grahl, S., Kirkland, A. and Villringer, A. (2013) Musical Feedback during Exercise Machine Workout Enhances Mood. Frontiers in Psychology, 4, 921. http://dx.doi.org/10.3389/fpsyg.2013.00921

[12] Ghetti, C.M. (2013) Effect of Music Therapy with Emotional-Approach Coping on Preprocedural Anxiety in Cardiac Catheterization: A Randomized Controlled Trial. Journal of Music Therapy, 50, 93-122. http://dx.doi.org/10.1093/jmt/50.2.93

[13] Fritz, T.H., Hardikar, S., Demoucron, M., Niessen, M., Demey, M., Giot, O., et al. (2013) Musical Agency Reduces Perceived Exertion during Strenuous Physical Performance. Proceedings of the National Academy of Sciences of the United States of America, 110, 17784-17789. http://dx.doi.org/10.1073/pnas.1217252110

[14] Sili, A., Fida, R., Proietti, D., Vellone, E. and Alvaro, R. (2013) Decreasing Preoperative Anxiety by Music: Experimental Study in a Vascular Surgery Unit. Assistenza infermieristica e ricerca: AIR, 32, 13-19.

[15] Nightingale, C.L., Rodriguez, C. and Carnaby, G. (2013) The Impact of Music Interventions on Anxiety for Adult Cancer Patients: A Meta-Analysis and Systematic Review. Integrative Cancer Therapies, 12, 393-403. http://dx.doi.org/10.1177/1534735413485817

[16] Blain-Moraes, S., Chesser, S., Kingsnorth, S., McKeever, P. and Biddiss, E. (2013) Biomusic: A Novel Technology for Revealing the Personhood of People with Profound Multiple Disabilities. Augmentative and Alternative Communication, 29, 159-173. http://dx.doi.org/10.3109/07434618.2012.760648

[17] Vollert, J.O., Stork, T., Rose, M. and Mockel, M. (2003) Music as Adjuvant Therapy for Coronary Heart Disease. Therapeutic Music Lowers Anxiety, Stress and Beta-Endorphin Concentrations in Patients from a Coronary Sport Group. Deutsche medizinische Wochenschrift, 128, 2712-2716.

[18] Boso, M., Politi, P., Barale, F. and Enzo, E. (2006) Neurophysiology and Neurobiology of the Musical Experience. Functional Neurology, 21, 187-191.

[19] McKinney, C.H., Tims, F.C., Kumar, A.M. and Kumar, M. (1997) The Effect of Selected Classical Music and Spontaneous Imagery on Plasma Beta-Endorphin. Journal of Behavioral Medicine, 20, 85-99. http://dx.doi.org/10.1023/A:1025543330939

[20] Habibipour, M., Habibipour, H., Habibipour, M. and Rejaee, A. (2008) Effect of Iranian Nonverbal Soft Music on the Reduction of Aggression among Boy Students of Mashhad Guidance School. Quarterly Educational Psychology, 3, 45-55.

[21] Smeijsters, H. and Cleven, G. (2006) The Treatment of Aggression Using Arts Therapies in Forensic Psychiatry: Results of a Qualitative Inquiry. The Arts in Psychotherapy, 33, 37-58. http://dx.doi.org/10.1016/j.aip.2005.07.001

[22] Saarikallio, S. and Erkkilä, J. (2007) The Role of Music in Adolescents' Mood Regulation. Psychology of Music, 35, 88-109. http://dx.doi.org/10.1177/0305735607068889

[23] Labbe, E., Schmidt, N., Babin, J. and Pharr, M. (2007) Coping with Stress: The Effectiveness of Different Types of Music. Applied Psychophysiology and Biofeedback, 32, 163-168. http://dx.doi.org/10.1007/s10484-007-9043-9 